Laboratorio de Arte, 7-1994 http://dx.doi.org/10.12795/LA.1994.i07.15

\title{
SOBRE LAS PINTURAS BAJOMEDIEVALES DE LA PARROQUIA SEVILLANA DE SAN PEDRO
}

\author{
POR Jóse María Medianero Hernández
}

Por los descubrimientos tras las respectivas obras de resturación y por la propia dinámica histórico-artística nos consta que las iglesias gótico-mudéjares hispalenses poseyeron en su gran mayoría pinturas murales ejecutadas en los últimos siglos medievales. Aunque generalmente estos restos han llegado a nosotros muy fragmentados y en precario estado de conservación, son importantes para rememorar el estado primigenio de estos templos, hoy transformados por las frecuentes remodelaciones y añadidos renacentistas, barrocos e incluso posteriores.

Es el caso de la iglesia de San Pedro, que como otras de Sevilla ha sufrido numerosas modificaciones y obras de restauración y consolidación; la última de magnitud se produjo en la década de los veinte de nuestro siglo.

Al parecer, en el verano de 1918 el preocupante estado por entonces de la parroquia de San Pedro desembocó en una amenaza seria de la integridad de la fábrica, por lo que fue precisa una intervención urgente, que a la postre condujo al hallazgo de abundantes estructuras góticas originales hasta ese momento ocultas por añadidos posteriores. Con esos descubrimientos aparecieron también restos de pinturas murales que demostraban la existencia de omato pictórico medieval anterior a las reformas de los siglos XVI,XVII y XVIII. Las obras de restauración total, incluso de altares, retablos y fachadas, fueron terminadas en 1924 y dirigidas por el Arquitecto Municipal Antonio Arévalo Martínez '.

De estas pinturas, las únicas noticias que poseemos se deben a unos apuntes inéditos de D. Francisco Collantes de Terán sobre la parroquia de San Pedro, como ya advirtió la Prfra. Dra. Teresa Dabrio en su monografía sobre dicha iglesia $^{2}$. Se trata de un trabajo mecanografiado fechado en su nota final en Madrid el 18 de Mayo de 1920, esto es, varios años antes de que concluyesen las

1. GUICHOT Y SIERRA, A. El Cicerone de Sevilla Sevilla,1925 Tomo I Pág. 64.

2. Estudio Histórico-Artístico de la Parroquia de San Pedro Sevilla, 1975 Pág. 13. 
obras de restauración recién iniciadas. Lleva por título: "Datos para una historia artística de la parroquia de San Pedro (Sevilla)".

Estimo de interés ofrecer aquí los párrafos de dicho trabajo referentes a las pinturas en cuestión, al ser el único testimonio escrito disponible sobre las mismas, para pasar luego a un análisis de estos datos ${ }^{3}$ :

\section{RETABLO PRIMITIVO}

Construida la iglesia de S. Pedro en el siglo XIV, no se hallan datos de un Retablo hasta mediados del siglo XVI.

¿Cual fue la decoración del presbiterio en este largo espacio de tiempo?

Solo un pequeño resto puede servirnos para establecer una hipótesis; son unas pinturas murales que se han encontrado al quitar las tablas de retablo actual en la parte semi circular (sic) del ábside.

Consisten en una faja longitudinal pintada al temple y con oro. Es una pintura decorativa, arquitectónica, representando una arquería de forma apuntada (Lámina XII).

Las escenas que encuadraba esta arquería son hoy imposibles de descifrar por la insignificancia de los restos: sólo se distingue la parte superior de una figura orante con las manos levantadas y los nimbos que rodean a tres cabezas, en la parte inferior, reconocibles por estar hechos en relieve invertido (rehundido en el estuco) que recuerdan los relieves de los frontales y antipendios.

La pintura se aplica sobre estuco formado por cal y paja.

Estas pinturas fueron cubiertas (probablemente en la época en que despojado el presbiterio del retablo primitivo aún no se habia colocado el nuevo retablo barroco) por pinturas barrocas de las que hoy se conserva un medallón representando a Jesús que entega las llaves a S. Pedro. Esto acabó de destruir la pintura primitiva bastante deteriorada ya por la colocación del retablo en el siglo XVI.

Podemos pues suponer el presbiterio primitivo de S. Pedro decorado con pinturas murales góticas de fines del siglo XIV.

En primer lugar despierta nuestro interés la referencia a una Lámina XII en el texto, pero el original no presenta ningún tipo de ilustración o fotografía. Supongo que se hace referencia a una reproducción realizada por miembros del por entonces llamado "Laboratorio de Arte de la Universidad de Sevilla" y de la cual se conserva un negativo en cristal en el Archivo Fotográfico del Departamento de Historia del Arte de nuestra Universidad, con fecha coetánea

3. He de agradecer públicamente al Prf. Dr. Antonio Collantes de Terán su amabilidad al facilitarme el original de los apuntes mencionados, sin el cual este modesto trabajo no hubiese sido posible. 
a la realización de los apuntes. Todo lo descrito por D. Francisco Collantes coincide con lo que muestra dicho negativo, cuyo positivo se reproduce en la Foto. 1 de este artículo.

Se hallaron, por consiguiente, dos decoraciones murales en el ábside de San Pedro al ser retirado el Retablo Mayor para su limpieza y consolidación hacia 1920: una inferior de características góticas y, superpuesta, otra de matices estilísticos barrocos. En la actualidad nada permanece de ellas o, si acaso quedase algo, se encuentra adherido a la parte trasera del retablo, que volvió a colocarse tras su restauración completamente adosado a la parte central del ábside, sin espacio intermedio alguno. Por los laterales sí existe un angosto espacio por el que se sitúan unas inseguras escalerillas de madera que suben hasta el ático del retablo.

Realizado el oscuro y polvoriento periplo sólo se aprecian tras el retablo paramentos enlucidos y encalados, labor ejecutada posiblemente durante la reinstalación del mismo. Sólo al inicio de la subida a partir de la portezuela izquierda del banco se observan unas superficies de mortero calizo muy fragmentado que pudieran ser restos de las preparaciones del muro para recibir las pinturas murales. En consecuencia, hoy por hoy, la fotografía antes mencionada y la descripción de D. Francisco Collantes son los únicos testimonios prácticos sobre las pinturas murales del ábside de la parroquia de San Pedro.

La datación de ambos murales -el gótico y el barroco- viene determinada por la colocación de los dos retablos que ha poseído la parroquia. El mural más primitivo ha de ser necesariamente anterior a la colocación del primer retablo -realizado por una serie de artistas entre los que destacan Nicolás de León y Alejo Fernández- en los años mediales del siglo XVI. Posteriormente, este retablo se desmontó, en 1653, para levantar en su lugar otro encargado a Felipe de Ribas que, al fin y a la postre, fue terminado por su hermano Francisco Dionisio de Ribas por fallecimiento del primero. No sólo por este óbito, sino por otros poblemas de diversa índole, se retrasó la colocación de este segundo retablo, que es el actual. El presbiterio de la iglesia de San Pedro debió de estar sin retablo varios años, quizás sólo con el banco del retablo antiguo y un crucificado mientras se esperaba la colocación del nuevo. En este momento, situado entre 1653 y 1660 aproximadamente, debieron cubrirse las pinturas góticas primitivas y sobre ellas pintarse algunas decoraciones de traza barroca, cuyo resto más significativo sería ese medallón con San Pedro que vio Collantes de Terán y que aparece en la fotografía ${ }^{4}$. En esta reproducción se advierte el nivel artístico discreto de estas pinturas y su sentido eminentemente decorativo.

Acerca de las pinturas góticas nos ha quedado un margen cronológico demasiado amplio: desde el siglo XIV, cuando se construye la parroquia de San Pedro, hasta la mediación del siglo XVI, cuando se monta el primer retablo como queda dicho. D. Francisco Collantes las fecha a fines del siglo XIV, aunque advierte de la precariedad

4. Sobre la colocación de los retablos Cfr. DABRIO, T. o. c. Págs. 44-49. Apéndice documental Doc. 32 y 33 . 
de lo conservado. Afirma también que técnicamente estaban realizadas "al temple y con oro" y sobre "estuco formado por cal y paja". Esto viene a encajar perfectamente con los procedimientos técnicos de la pintura mural hispalense bajomedieval, que procedía a través de temples de cola o yema de huevo sobre capas de recepción de pigmentos muy ricas en cal y con la inclusión de pajitas para dar mayor flexibilidad a los morteros frente a los cambios de humedad y temperatura. Además de la aplicación de nimbos trabajados sobre el estuco con fuertes gofrados como también anota el mismo autor ${ }^{5}$.

Estas pinturas aparecen por debajo y situadas en la parte inferior del medallón de la Entrega de las llaves a San Pedro antes comentado y, en verdad, lo único que puede apreciarse en la fotografía es lo que ya anotó Colantes de Terán: una arquería de ojivas goticista y unas manos alzadas que pudieran identificarse como las de unos orantes o donantes.

Desde luego muy poco es para poder apuntar una cronología determinada; $D$. Francisco Collantes se decidió por datarlas a fines del siglo XIV, quizás llevado por la hipótesis de que estos murales se realizaran tras la construcción de la iglesia y como "retablo" pictórico primitivo de la misma. Esto no tuvo que ser necesariamente así; la traza decorativa de las ojivas lobuladas y una especie de cenefa calada superior resultan una obra de cierta complejidad y gusto evolucionado dentro del gótico. Este matiz, y el hecho de que se conserven en otro lugar del templo murales de fines del siglo XV, como inmediatamente veremos, propicia la hipótesis de que estas pinturas pudieran haberse ejecutado también en la cronología antedicha y que fuesen de un marchamo estilístico cercano a lo hispano-flamenco.

Efectivamente, en el segundo pilar orientado hacia la Nave del Evangelio y en su par colocado hacia la Nave de la Epístola se conservan todavía dos murales representativos de San Sebastián y Santa Catalina respectivamente. No obstante, se hallan en un estado muy poco adecuado para su estudio debido a una pésima restauración realizada en 1966, cuyo autor -A. Armenta- se atrevió incluso a firmar. También aparecieron en las obras iniciadas poco antes de 1920 y de nuevo D. Francisco Collantes nos da noticia de estas pinturas en su trabajo sobre la parroquia:

\section{FRESCOS DE LOS PILARES}

En el segundo pilar de ambos lados de la nave central se descubrieron al levantar el revoque, dos frescos muy deteriorados (habian sido picados para que agarrase el yeso) representando a S. Sebastián y Sta. Catalina.

El de S. Sebastián (lado Evangelio) representa al santo al estilo de la época, en traje cortesano, con espada al lado izquierdo, llevando en la mano del mismo

5. Vid. mi Tesis Doctoral inédita "La Pintura Trecentista en Andalucía" defendida en la Facultad de Geografía e Historia de la Universidad de Sevilla en Octubre de 1987. Tomo I Págs. 81-109 passim. 
lado (que tiene enguantada) el arco, símbolo de su martirio, mientras que con la derecha lleva una cruz; en este mismo lado del pecho tiene clavada una saeta. La cabeza es barbada. (Dimensiones: 1'65 X 0,60 mtrs).

El fresco que representa a Sta. Catalina muestra a la santa con riquísima corona, abierto en su mano izquierda el libro que debió servirle en sus discusiones con los filósofos gentiles y en la derecha la espada instrumento de su martirio. Destácase intensamente el rojo del manto sobre la túnica ricamente bordada en oro.

¿Quién fue el autor de estos frescos?

Ante todo hagamos una labor de selección fijando en lo posible los caracteres de época de las pinturas.

Basta contemplarlas para comprender que Van-Eyck ha llegado a España. Las cabezas de las figuras son flamencas ó alemanas; el gorro ó sombrero redondo del S. Sebastián se halla en los cuadros de los primeros flamencos; el alargamiento y finura de las manos es también característico.

En cuanto a la técnica, se nota todavía al aprendiz que aún no ha llegado a dominar el nuevo procedimiento: existen veladuras al óleo de un tono rojizo sobre el oro de las túnicas y otras partes de las figuras.

Debieron pintarse estos frescos hacia los últimos años del siglo XV cuando ya la influencia de Van-Eyck y la popularidad de los primitivos flamencos ha llegado a Sevilla.

Busquemos ahora que pintor pudo trabajar en S. Pedro en ese periodo.

Florecía por entonces en Sevilla el patriarca de la escuela sevillana de pintura, JUAN SANCHEZ DE CASTRO en el que los caracteres flamencos predominan en sus principios de un modo marcadísimo. De él tenemos 8 tablas procedentes de S. Benito de Calatrava, conservadas en depósito en el Museo de Pinturas de Sevilla. Representan 8 santos de gran devoción y entre ellos también S. Sebastián y Sta. Catalina. (Lámina XVI).

Pues bien, comparando los frescos de S. Pedro con estas dos tablas, se ve tal unidad de realización de las figuras y de tipo, que no es posible dejar de pensar en una unidad de taller y quizás de artista. Hay hasta un cierto amaneramiento en la disposición de las figuras sobre todo en las (sic) de S. Sebastián: todos los detalles se hallan repetidos: la flecha clavada, el arco, la espada, el guante de la mano izquierda.

Desde luego la obra de las tablas del Museo revelan un producto más maduro del artista, que en los frescos de S. Pedro se muestra todavía vacilante, en los comienzos de una técnica nueva que luego debía producir en sus manos maravillosas obras.

Otra vez existe una mención de lámina sobre estos murales y, efectivamente, en el Archivo Fotográfico del Departamento de Historia del Arte de la Universidad de Sevilla se conservan varios negativos que parecen responder a esta referencia y reproducimos en este artículo los dos en mejor estado (Foto. 2 y 3 ). 
A través de la descripción de Collantes de Terán, las fotografías antedichas y, en fin, lo que aún puede atisbarse en el templo se consigue llegar a un análisis medianamente fiable sobre las obras en cuestión.

Sobre la técnica utilizada es imposible manifestarse por el estado actual de los murales. D. Francisco Collantes nos habla de "frescos", pero este procedimiento parece muy poco probable; debe utilizar este término, como era corriente en muchos autores de la época, asimilándolo en su sentido lato con la palabra "mural". Como ya advertí en otro lugar, el procedimiento del fresco puro -el "buen fresco" siguiendo la expresión italiana- no parece introducirse en Sevilla sino hasta mediados del siglo XVI de la mano de Luis de Vargas ${ }^{6}$.

Es muy interesante la precisión que expone sobre la utilización de "veladuras al óleo", particularidad que sí parece factible, pues sabemos de la utilización en el ámbito hispalense de pigmentos diluidos con aceite de linaza en la pintura mural ${ }^{7}$. Sin embargo, no han de olvidarse los probables retoques y restauraciones de estas pinturas murales desde su realización; por ejemplo, según la documentación parroquial, en 1689 un pintor llamado Luis Navarro "renovó" estos murales ${ }^{8}$. De todas maneras, puede suponerse sin temor a errar en demasía que la técnica primitiva de ejecución debió ser la siguiente: una preparación inicial de tipo fresco, siguiendo con pintura "a secco" a base de temple y óleo, además de algunas aplicaciones de panes de oro hoy perdidas.

Tanto por la iconografía como por el estilo que se desprende de estos murales su encuadre dentro de la etapa Hispano-Flamenca parece indudable. Y con razón Collantes de Terán compara estas pinturas con el retablo que, procedente de San Benito de Calatrava, se exhibe hoy en el Museo de Sevilla ${ }^{9}$, ponderando, sobre todo, la similitud del San Sebastián con la representación del mismo santo en el retablo antedicho. Desde luego San Sebastián posee una iconografía muy similar como santo caballero joven y apuesto. Sin embargo, pueden concretarse algunas diferencias: el ropaje del San Sebastián de la parroquia de San Pedro parece menos lujoso y sin duda más corto que el de su homónimo del Museo; el tocado de la cabeza es también algo distinto, más ampuloso en el San Sebastián de la parroquia de San Pedro y, principalmente, el báculo abalaustrado en su parte superior y terminado en cruz que posee el mural de San Pedro y que no tiene el San Sebastián del Museo. Coinciden, eso sí, en varios aspectos: la flecha clavada en el mismo lugar, el rostro barbado e idealizado y, quizás, el suelo en perspectiva acusada, aunque el estado de esta parte en la obra de San Pedro dejaba mucho que desear cuando apareció.

6. IBIDEM. Tomo I Pág. 105.

7. MEDIANERO HERNANDEZ, J.M" "Aportaciones documentales sobre la técnica de la pintura hispalense a fines de la Edad Media" en la Rev. Laboratorio de Arte nº 6 Sevilla, 1993 Págs. 72-4.

8. Vid. DABRIO, T. Estudio Histórico-Artístico de la parroquia de San Pedro o. c. Pág. 103.

9. Reproducidas y comentadas las tablas en MORENO MENDOZA, A. et Alter Museo de Bellas Artes de Sevilla Sevilla, Ed. Gever,1991 Vol. II Págs. 24 y 26-7. 
En cuanto a la figura de Santa Catalina de Alejandría, aunque participa de un espíritu artístico similar, es distinta en las dos realizaciones, tanto en el vestuario comowen los detalles: así la corona, el giro de la cabeza y, sobre todo, el libro que porta la de San Pedro y que no aparece en la Santa Catalina del Museo.

Desde luego se trata de un autor de formación muy similar, dentro de un estilo Hispano-Flamenco plenamente asimilado, fechable en los últimos años del siglo XV. D. Francisco Collantes apunta, como no, el nombre del "Patriarca" de la pintura sevillana Juan Sánchez de Castro, apoyándose en las similitudes con el retablo de San Benito que adjudica sin dudas a este autor.

No existen certidumbres documentales a este respecto; en el estado actual de conocimientos sobre la etapa tenemos una obra anónima, como otras muchas dentro de la órbita de este significativo pintor mal conocido. Además es menester no olvidar la amplia nómina de pintores que en las postrimerías de la centuria antedicha poseía ya Sevilla, de lo cual es prueba fehaciente, más que las obras conservadas que por los azares del tiempo y de los hombres son relativamente escasas, la abundancia de nombres de pintores en la documentación hispalense de la época.

No contamos, en mi opinión, con razones suficientes para afirmar una cierta impericia por parte del autor ("se nota todavía al aprendiz que aún no ha llegado a dominar el nuevo procedimiento") o una inferioridad respecto a las tablas del Museo ("producto más maduro del artista"). Lo que resulta evidente es una clara diferenciación técnica: pintura mural en el caso de San Pedro y pintura en tabla en la obra del Museo, más lucida por el colorido ésta última y mejor conservada. Por el contrario, son parangonables en cuanto a calidad y alcances artísticos.

En consecuencia, disponemos de la constancia de unas pinturas murales en la parroquia de San Pedro, restos quizás de un conjunto mural llevado a cabo a fines del siglo XV y dentro de unas trazas netas Hispano-Flamencas. Pinturas de calidad nada despreciable dentro de las cotas usuales de la pintura hispalense del momento y relacionables con la figura de Juan Sánchez de Castro, que, probablemente, engloba y personifica a varios maestros seguidores de una línea pictórica muy similar. Conjunto éste de San Pedro que demuestra bien a las claras la pervivencia de la práctica de la pintura mural en los templos hispalenses también en las postrimerías de la etapa medieval. 


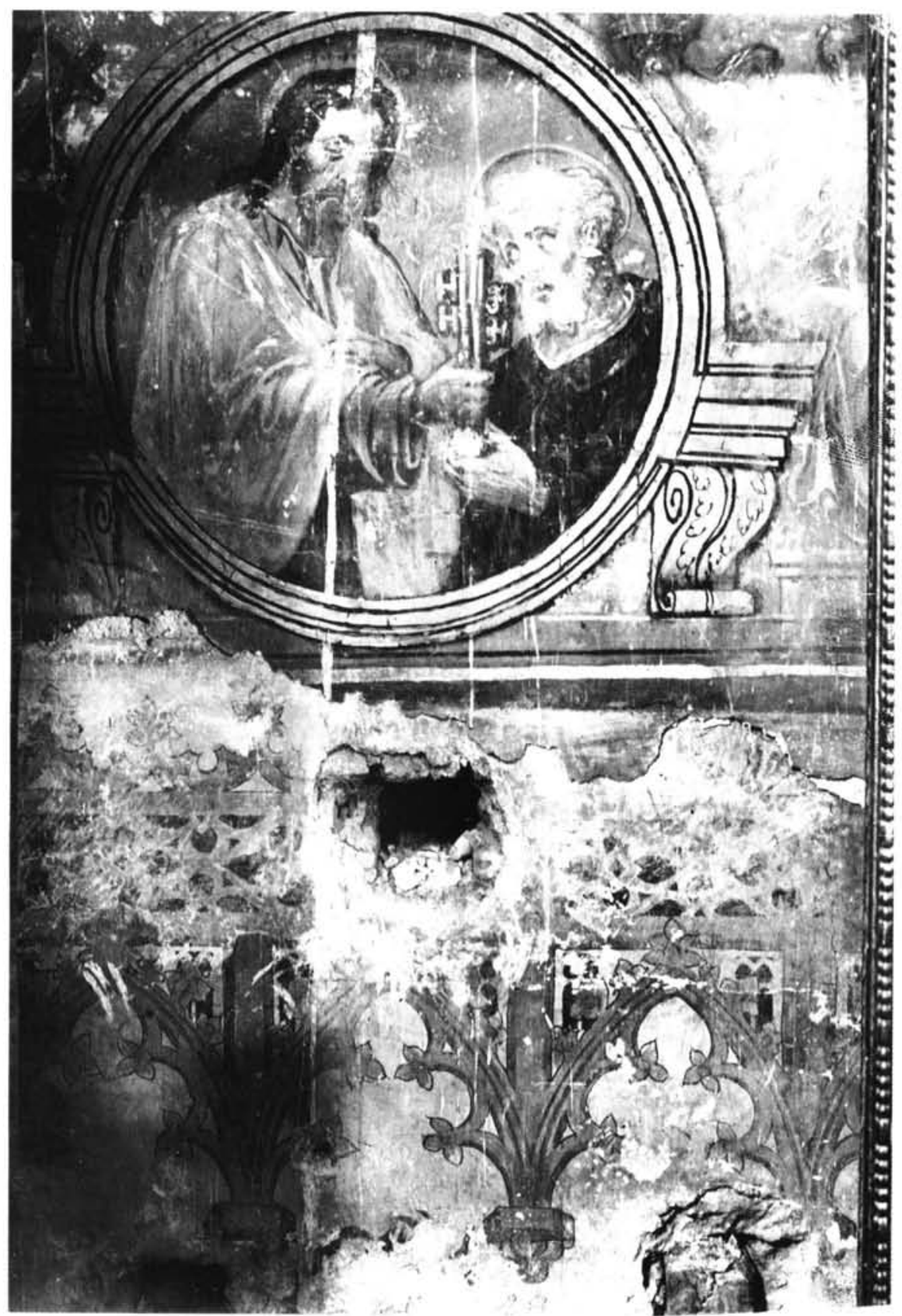

1.- Pinturas murales descubiertas en el ábside de la parroquia de San Pedro (Archivo Fotográfico del Departamento de $\mathrm{H}^{\mathrm{a}}$ del Arte. Universidad de Sevilla). 


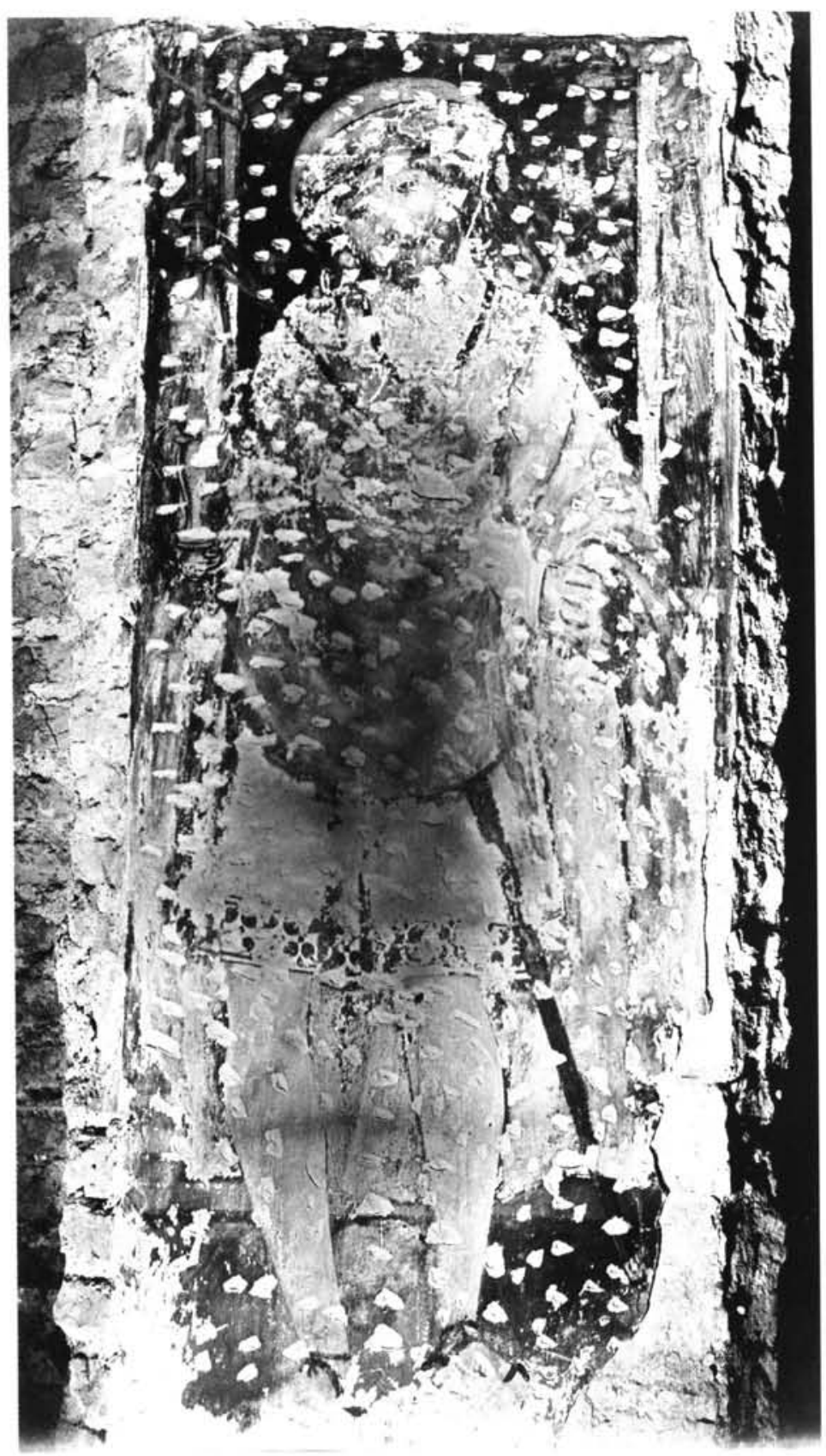

2.- Mural con la figura de San Sebastián (Archivo Fotográfico del Departamento de $\mathrm{H}^{\mathrm{a}}$ del Arte. Universidad de Sevilla). 


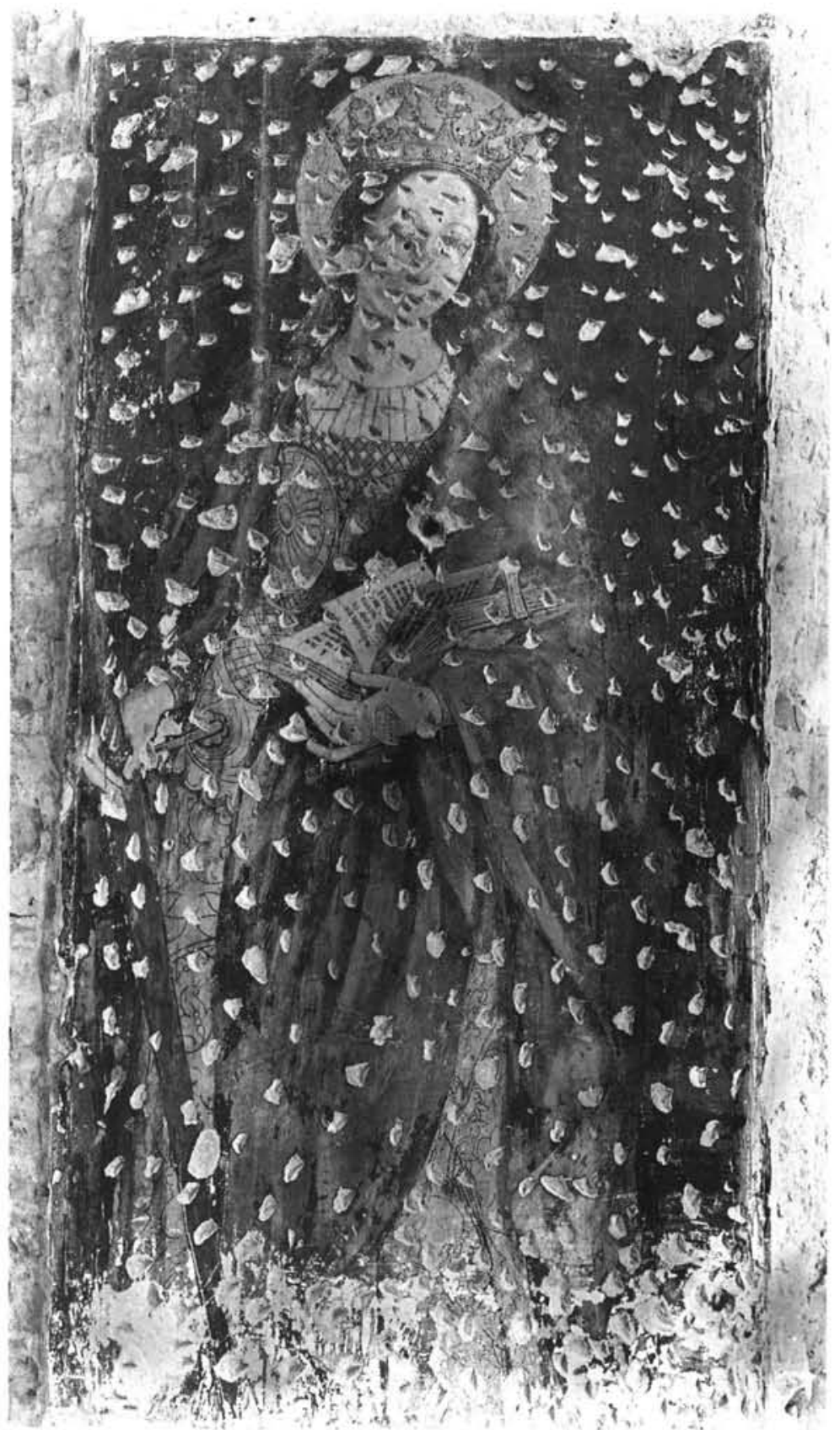

3.- Mural con la figura de Santa Catalina (Archivo Fotográfico del Departamento de $\mathrm{H}^{\mathrm{a}}$ del Arte. Universidad de Sevilla). 


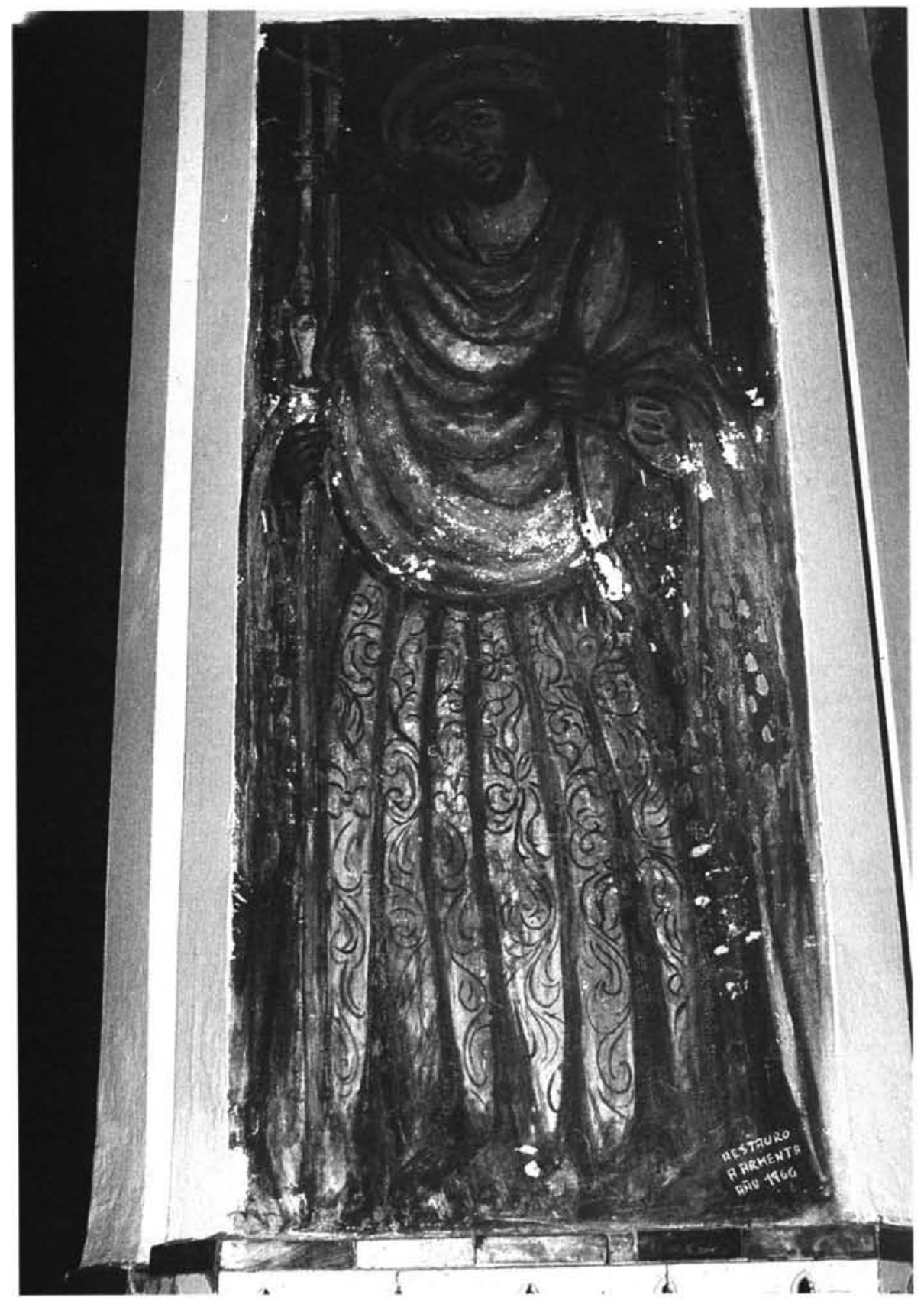

4.- Mural de San Sebastián. Estado actual. 


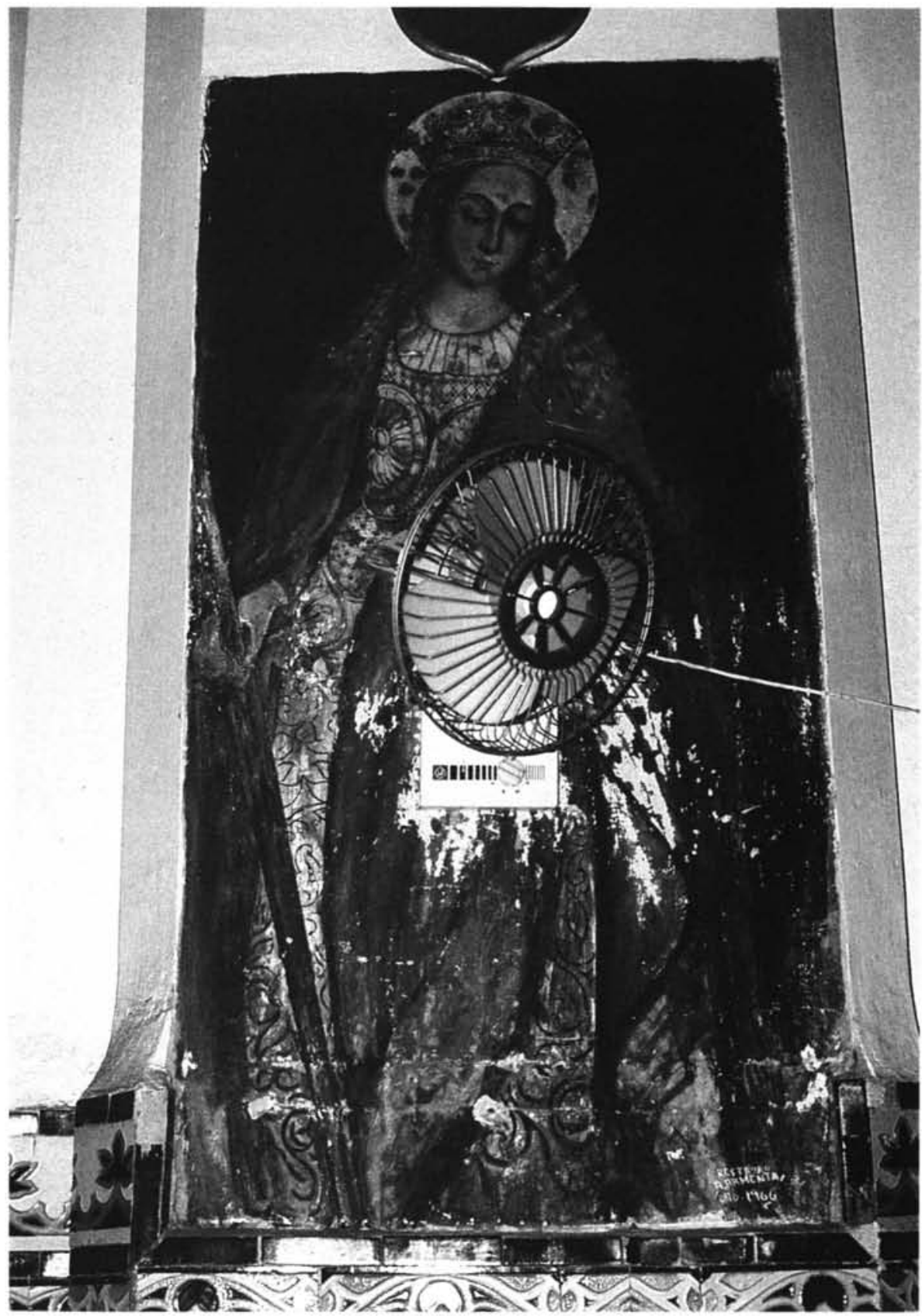

5.- Mural de Santa Catalina. Estado actual. 